\title{
Living and Caring After a Stroke
}

\author{
Viver e Cuidar Após o Acidente Vascular Cerebral \\ Vivir y Cuidado Después del Accidente Cerebrovascular \\ Inês Filipa Guerra da Silva*; Conceição Fernandes da Silva Neves**; \\ Ana Cláudia Gomes Vilela***; Lília Marisa Dias Bastos***; \\ Marina Ivone Lamego Silva Henriques****
}

\begin{abstract}
Background: Stroke may cause permanent changes in the patient and in the caregiver and, consequently, in their quality of life.

Objectives: To assess the perception of quality of life of caregivers and stroke patients hospitalized in the Stroke Unit of the Hospital Center of Baixo Vouga.

Methodology: Quantitative, descriptive and cross-sectional study, with a non-probability convenience sample.

Results: The socio-demographic and clinical variables influence the quality of life. Two months after the stroke, both the patients and the caregivers have worse quality of life.

Conclusion: When comparing patients' and caregivers' quality of life at the time of hospitalization and at the 2-month follow-up (after discharge), we concluded that both have worse quality of life two months after the stroke. We also concluded that the caregivers have better quality of life than the patients, although this difference was not statistically significant.
\end{abstract}

Keywords: stroke; quality of life; caregivers; nursing; patient

\section{Resumo}

Enquadramento: O acidente vascular cerebral (AVC) pode provocar alterações permanentes no paciente e no prestador de cuidados (PC) e consequentemente na qualidade de vida (QV).

Objetivos: Avaliar a perceção da QV dos prestadores de cuidados e dos pacientes com AVC internados na Unidade de Acidentes Vasculares Cerebrais do Centro Hospitalar do Baixo Vouga.

Metodologia: Estudo quantitativo, descritivo e transversal, com amostra não probabilística por conveniência.

Resultados: As variáveis sociodemográficas e clínicas influenciam a QV. Dois meses após o AVC, tanto os pacientes como os PC apresentam pior QV.

Conclusão: Ao compararmos a QV do paciente e do PC tanto no momento de internamento como na reavaliação aos 2 meses (após a alta) concluímos que ambos têm pior QV aos 2 meses após o AVC. Concluímos ainda que o PC apresenta melhor QV do que o paciente, no entanto a diferença não é estatisticamente significativa.

Palavras-chave: acidente vascular cerebral; qualidade de vida; cuidadores; enfermagem; paciente

\footnotetext{
* Lic., RN, Hospital Center of Baixo Vouga, EPE, 3814-501, Aveiro, Portugal [inexsilva@hotmail.com]. Contribution to the article: literature search; data collection; statistical treatment and assessment; key role in data analysis and discussion; article writing

Address for correspondence: Avenida Calouste Gulbenkian, lote 60 B, 3814-501, Aveiro, Portugal.

** MSc., Head Nurse, of Medical Specialties / Stroke Unit / Medicine 3, Hospital Center of Baixo Vouga, EPE, 3814.501, Aveiro, Portugal [conceicao7neves@ hotmail.com]. Contribution to the article: literature search; data collection; statistical treatment and assessment; key role in data analysis and discussion; article writing. *** RN, General Care Nurse, Hospital Center of Baixo Vouga, EPE, 3814-501, Aveiro, Portugal [laujo@ portugalmail.com]. Contribution to the article: literature search; data collection; statistical treatment and assessment; key role in data analysis and discussion; article writing

***** MSc., Rehabilitation Nurse, Unit of Medical Specialties / Stroke Unit, Hospital Center of Baixo Voug EPE, 3814-501, Aveiro, Portugal [liliabastos1@sapo.pt]. Contribution to the article: literature search; data collection; statistical treatment and assessment; key role in data analysis and discussion; article writing. ****** RN, General Care Nurse, Hospital Center of Baixo Vouga, EPE, 3814-501, Aveiro, Portugal [marinailsh@ hotmail.com]. Contribution to the article: literature search; data collection; statistical treatment and
} assessment; key role in data analysis and discussion; article writing.

\section{Resumen}

Marco contextual: El Accidente Cerebro Vascular causa cambios permanentes en vida del paciente y del cuidador y en consecuencia en la calidad de vida de los mismos.

Objetivos: Evaluar la calidad de vida de los cuidadores e de los pacientes con accidente cerebrovascular ingresados en la Unidad de accidente cerebrovascular del Centro Hospitalar do Baixo Vouga

Metodología: Estudio cuantitativo, descriptivo y transversal, com amuestra non probabilística por conveniencia.

Resultados: Las variables sociodemográficas y clínicas influyen en la calidad de vida. Después de dos meses los pacientes y el cuidador tienen una peor calidad de vida.

Conclusión: Mediante la comparación de la calidad de vida del paciente con el cuidador tanto en el momento de la hospitalización como en la revaluación a los 2 meses (después del alta), concluimos que ambos tienen peor calidad de vida, después del accidente cerebrovascular. Aún concluímos que el cuidador tiene una mejor calidad de vida que lo paciente, pero la diferencia no es estadísticamente significativa.

Keywords: accidente cerebrovascular; calidad de vida; cuidadores; enfermería; paciente

Received for publication:31.08.15

Accepted for publication: 01.02 .16 


\section{Introduction}

Stroke is the leading cause of death and disability in Portugal. Stroke survivors become increasingly dependent on self-care, with need for permanent support, which has a major impact on their lives and on their relatives' lives. The physical dependence brings about social changes, which are often translated into isolation, and economic and emotional changes that will inevitably reduce the quality of life (QoL) of these people.

QoL has become a priority in health services through health promotion and disease prevention. It is critical to empower people to provide care by promoting the physical, mental and social well-being of patients and caregivers, thus helping to improve the QoL.

As a result of our daily work at a Stroke Unit, we are aware of the impact of a stroke on the family structure. For this reason, we feel the need to assess QoL, as well as the difficulties experienced by the caregivers while caring for the dependent person.

As a multidimensional concept, QoL assessment cannot be limited to the assessment of the results achieved with the treatment and medical interventions; rather, it should encompass the impact of the disease and the treatment on the different dimensions of the individual.

This study was structured based on the following objectives: to assess how stroke patients perceive QoL; to assess how caregivers of stroke patients perceive QoL; to analyze the association between the sociodemographic variables and the QoL of stroke patients; to analyze the association between the sociodemographic variables and the QoL of caregivers of stroke patients; and to analyze the association between the clinical variables and the QoL of stroke patients.

\section{Background}

According to data released by Statistics Portugal (INE; 2010), the national aging index has been increasing with an average life expectancy (2007-2009 triennium) of 75.8 years for men and 81.8 for women.

While addressing the issue of population aging, we must mention that the risk of stroke increases with age. According to Phipps, approximately 60\% to 70\% of strokes occur in individuals over 65 years of age (cited in Marques, 2012).

Ischemic or hemorrhagic stroke corresponds to an insufficient supply of blood and its constituents to a particular area of the brain. The various studies consulted mention that around 15\% to 25\% of strokes are hemorrhagic strokes and $75 \%$ to $85 \%$ are ischemic strokes.

Risk factors such as hypertension, diabetes, dyslipidemia, smoking, alcoholism, cardiac disease, among others, are predictors of stroke; however, it is important to mention that a high percentage of strokes are of unknown etiology (Batista, 2012).

Many stroke patients die instantly or in the following months due to stroke-related complications.

Neuropsychiatric disorders such as depression may also occur, although their etiology is still uncertain (Alves, Rodrigues, Fernandes, Vieira, \& Fragoeiro, 2012). However, the physical dependence seems to be the most worrying consequence for the patient and the caregiver due to the changes in their daily lives.

Studies show that most physically impaired patients are cared for at home by their family. Therefore, as according to the Nursing Council of the Ordem dos Enfermeiros (2009), to speak of the stroke patient implies speaking of the patient-family caregiver binomial

The caregivers of dependent people play a key role in the continuity of care when the patients return home, thus emerging the figure of the caregiver.

As stroke is a potentially disabling disease, nurses are expected to actively contribute to empower people to cope with the disease, since the care receiver is also a member of that family and will have to handle the challenges when returning home. Therefore, the nurse plays a key role in the therapeutic relationship, contributing to the process of adaptation to the new life condition and, consequently, to their QoL (Ordem dos Enfermeiros, 2009).

We underline that the overburden experienced by the so-called caregivers is often overlooked, and they are the central point of reference in the care process, suddenly and unexpectedly assuming responsibility for care, without being prepared.

The World Health Organization (WHO) defined QoL as "the individuals' perception of their position in life in the context of the culture and value systems in which they live and in relation to their goals, expectations, 
standards and concerns" (p. 3). However, Leal (2008), in a study developed with the purpose of reassessing the QoL concept, proposes a more comprehensive definition:

Quality of life is the result of the sum of the physical, social, cultural, spiritual and economic environment where the individual is inserted, of the lifestyles adopted, of his/her actions and reflection about the self, the others and the surrounding environment. It is also the sum of the positive expectations toward the future. (p. 5) Health-related QoL can be considered as the value assigned to life, as modified by the impairments, perceptions and social conditions that are influenced by disease, treatments and the political and economic organization of the health care system (Campos \& Neto, 2008). The study of QoL allows understanding the impact of the disease on the activities of daily living.

\section{Research questions}

The following research questions were formulated for this article:

- Which factors influence the perception of QoL of stroke patients?

- Which factors influence the perception of QoL of caregivers of stroke patients?

- Do the sociodemographic variables influence the QoL of stroke patients?

- Do the sociodemographic variables influence the QoL of stroke patients?

- To what extent do the clinical variables influence the QOL of stroke patients?

\section{Methodology}

This quantitative, descriptive and cross-sectional study aims to describe the perception of QoL of patients and caregivers, analyze the influence of the sociodemographic variables on the caregiver and the patient and analyze the influence of the clinical variables on the patient.

Knowing that it takes time, availability and many resources to study a population, we chose to select a sample.

This was a non-probability convenience sample composed of all patients diagnosed with a stroke who were admitted to the Stroke Unit of the Hospital Center of Baixo Vouga (CHBV) between August 2010 and December 2012 and respective caregivers. The criterion for inclusion in the study was the occurrence of ischemic or hemorrhagic stroke with subsequent moderate or high dependence on self-care. The authors of this study applied 55 questionnaires to both patients and caregivers.

The dependent variable is the QoL and the independent variables are the sociodemographic and clinical variables. The data collection tools used in the first moment of this study were a grid to assess the caregivers' knowledge, and the patients' clinical profile and risk factors; the patients' and the caregivers' sociodemographic profile; the application of the Portuguese version of the abbreviated instrument of quality of life WHOQOL-bref of the World Health Organization (WHOQOL-bref) to patients and caregivers.

The first moment of data collection also included activities developed by the nurse responsible for the patient: Assessment of the patient and respective family of reference to identify the necessary educational interventions, while confirming the patient's family support; assessment of the housing conditions, to schedule appropriate educational interventions; request for a social worker (when necessary); collaboration with the physician (conditions for discharge home); schedule of educational interventions for the patient and the caregiver; implementation of educational interventions and later assessment (assessment of knowledge and skills); schedule of the follow-up date (2 months after clinical discharge).

At follow-up (2 months after clinical discharge), the following tools were applied: the patient's clinical profile; the Carer's Assessment of Difficulties Index (CADI) and the Questionnaire for Assessment of Informal Caregiver Burden (Questionário de Avaliação da Sobrecarga do Cuidador Informal - QASCI) to the caregivers; and the WHOQOL-bref scale to the patient and the caregivers.

The QASCI was developed by Martins, Ribeiro, and Garrett (2003). It includes 32 items divided into seven dimensions and assessed on an ordinal scale ranging between 1 and 5 .

The CADI was developed by Brito (2000) with the purpose of facilitating the identification of the most common type of difficulties in situations of care 
provision to elderly relatives, as well as of how the caregivers perceive and experience these difficulties. The WHOQOL-bref assesses the perception of QoL. It was developed by the World Health Organization and is composed of 26 questions, with two general questions relating to QoL and 24 questions divided into four domains: physical, psychological, social, and environment.

Participation was voluntary, and all study participants were ensured the confidentiality of their personal data.

In order to maintain a rigorous ethical conduct in the procedures used throughout the research process, we developed a study protocol which was submitted to and approved by the Ethics Committee. Formal authorization was also requested to the director of the Neurology Unit and subsequently to the Administration Board of the CHBV. All patients signed the informed consent to participate in the study.

Data were collected based on a procedure (protocol) composed of questionnaires and scales that allowed for the application of questionnaires to patients and respective caregivers, whose answers remained anonymous.

The data collected were statistically analyzed using SPSS 21.0 (Statistical Package for the Social Sciences). Several statistical procedures were used throughout the study according to the type of variables and the objectives of analysis.

\section{Results}

Out of the 55 patients, 30.9\% were female and $69.1 \%$ were male.

The patients' age ranged between 44 and 92 years, with $58.2 \%$ of the participants aged 70 years or older. Out of the 55 caregivers, $81.5 \%$ were female and $18.5 \%$ were male. The caregivers' age ranged between 28 and 78 years, with $54.8 \%$ of the participants being under 50 years old.

In relation to the family situation, most stroke patients were married (68.5\%), 25.9\% were widowed, 1.9\% were cohabiting and $1.9 \%$ were single/separated.
The majority of the caregivers were married (72.2\%), $13 \%$ were single, $7.4 \%$ were divorced and $7.4 \%$ were cohabiting.

With regard to the professional situation of the stroke patients, $72.2 \%$ were retired, $22.3 \%$ were paid workers, $1.9 \%$ were unemployed, and $1.9 \%$ were homemakers, disabled people or people on sick leave.

With regard to the professional situation of the caregivers, 29.6\% were employees, 20.4\% were self-employed or liberal professionals, $16.7 \%$ were homemakers, $14.8 \%$ were unemployed, $13 \%$ were retired and $5.6 \%$ were disabled or on sick leave.

In relation to the level of education, $71.8 \%$ of the patients had basic education, $17 \%$ had no education, $5.7 \%$ had secondary education (12 ${ }^{\text {th }}$ grade), and $5.7 \%$ had higher education. Among caregivers, 70.4\% had basic education, around 13\% had secondary education (12 ${ }^{\text {th }}$ grade), $5.6 \%$ had no education, and $11.2 \%$ had higher education.

All stroke patients and caregivers were Caucasian.

With regard to the marital status, $46.3 \%$ of the stroke patients lived with their spouse, $24.1 \%$ with their spouse and relatives, $20.4 \%$ lived with relatives other than their spouse, $7.4 \%$ lived alone, and 1.9\% lived with other people.

Around $64.8 \%$ of caregivers lived with their spouse, $14.8 \%$ lived with relatives other than their spouse, 13\% lived with their spouse and relatives, 5.6\% lived alone and $1.8 \%$ lived with friends.

In relation to the type of stroke, $76.4 \%$ of the patients were diagnosed with ischemic stroke and $23.6 \%$ with hemorrhagic stroke.

The diagnosis was confirmed in $98.2 \%$ of the cases through clinical criteria and computerized tomography (CT scan). In 1.8\% of cases, magnetic resonance imaging (MRI) was also used.

In relation to the clinical variables, $12.7 \%$ of the patients were smokers and $41.8 \%$ mentioned drinking alcohol. In relation to the Body Mass Index, about $75 \%$ of the participants were overweight.

In this sample, $85.5 \%$ of the participants had risk factors: $67.9 \%$ of hospitalized patients had high blood pressure (HBP), $47.7 \%$ had dyslipidemia, $4.2 \%$ had diabetes, $6.4 \%$ were obese and $25.5 \%$ were obese and had other risk factors, as can be seen in Figure1. 


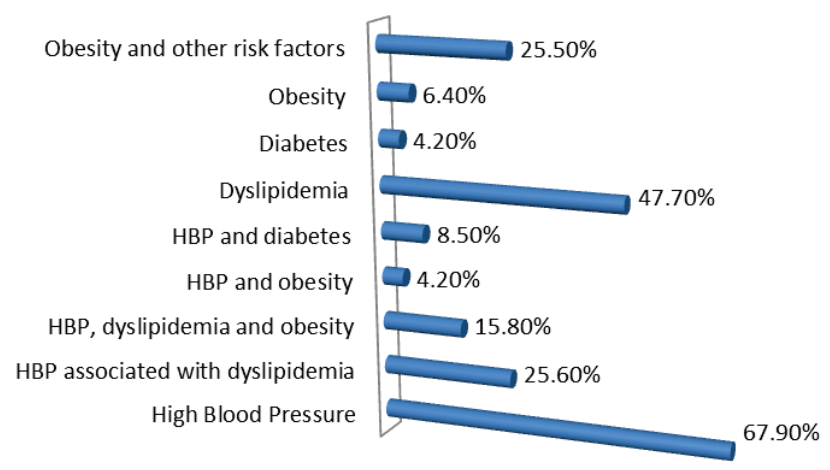

Figure 1. Risk factors.

During hospitalization, $76.4 \%$ of the patients had no complications, whereas $23.7 \%$ had complications, with $7.3 \%$ of them being related to respiratory infections.
For the patients admitted to the study, we assessed the knowledge of the caregivers through a checklist built for that purpose, so as to schedule the necessary educational interventions (Figure 2).

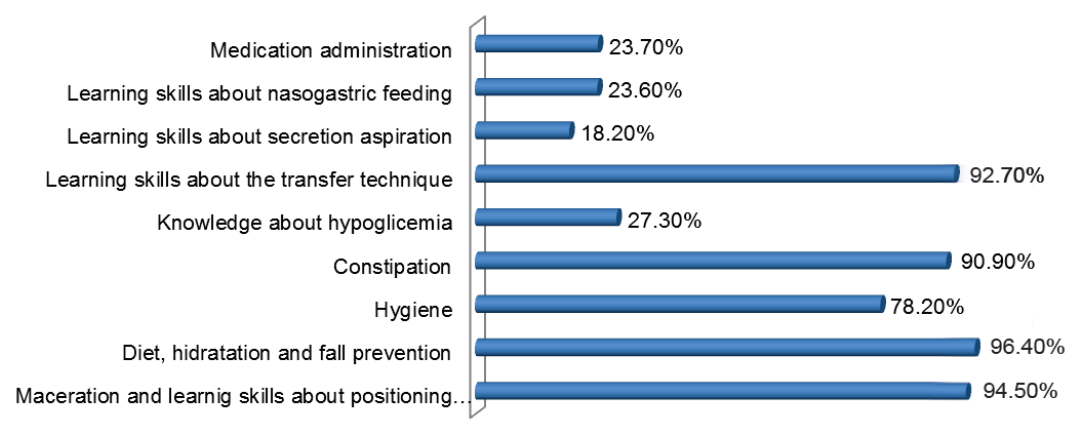

Figure 2. Lack of knowledge of caregivers.

We observed that $98.2 \%$ of the participants were unaware of the causes of the stroke, the symptoms, what they could do to help a stroke patient, the psychological implications, had received no educational intervention on how to care for a stroke patient, as well as on the management of the therapeutic regimen (diet, physical activity, living with a stroke, guidance after stroke, and smoking) and on prevention of pressure ulcers.

In addition, 49.1\% had never attended consultations of clinical psychology.

In relation to social assistance, $94.5 \%$ mentioned receiving no support.
We noticed that, after discharge, $3.6 \%$ of patients were readmitted due to respiratory infection or febrile syndrome. We found that $18.2 \%$ of the patients used the emergency unit for various reasons, namely because of respiratory infection, urinary infection, new stroke, tremors and vomiting.

Two months after discharge, we were not able to assess all patients and caregivers for different reasons: $25.5 \%$ of the patients remained in the Integrated Long-Term Care Unit, $25.5 \%$ were at home (14.6\% in their own house and $10.9 \%$ at their relatives' house), in $30.8 \%$ of the cases we were unable to establish contact, 1.8\% had suffered another stroke and were hospitalized, and 16.4\% had died (Table 1). 
Table 1

Patients' situation 2 months after discharge

\begin{tabular}{lc}
\hline Patients' situation 2 months after discharge & $\%$ \\
\hline Integrated Long-Term Care Unit & 25.50 \\
Home: own house & 14.6 \\
Home: relatives' house & 10.9 \\
Unable to establish contact & 30.80 \\
New stroke / Hospitalization & 1.80 \\
Death & 16.40 \\
\hline
\end{tabular}

In relation to weight, $54.5 \%$ of the respondents had normal weight, and $45.5 \%$ were overweight. In relation to smoking, we only obtained data from $61.8 \%$ of the patients and all of them were not smoking at the 2-month follow-up after the stroke. In relation to alcohol consumption, only $61.8 \%$ answered the question and $11.8 \%$ of these mentioned drinking some alcohol.

In relation to the CADI scale, we found that the caregivers struggled with some issues. More than 50\% of caregivers reported some difficulties or that they were very disturbed for taking care of their relatives. In many of the questions, no caregiver indicated that, in their situation, it had not happened or that it happened but did not disturb them.

When we calculated the CADI dimensions, we noticed that most of the caregivers reported facing major difficulties and being highly overwhelmed due to the lack of professional support, patient-related problems and inadequate family support.

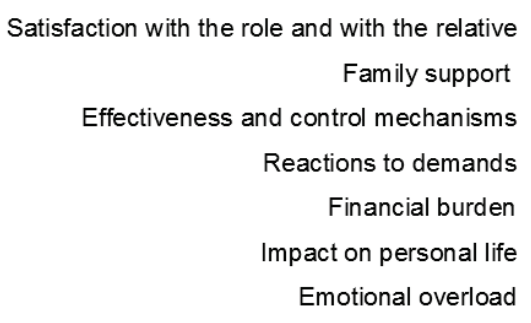

The dimensions also reflect the scores of the respective questions, because, in all dimensions, most caregivers $(>72.6 \%)$ reported that the situation of the stroke patient is very or somehow disturbing. We explored the existence of a statistically significant difference between male and female caregivers and the dimensions of this scale and, although there was a difference in all dimensions, it was not a statistically significant difference $(p>0.05)$.

We assessed the physical, emotional and social impact of the role of caregiver through the QASCI questionnaire, which included a series of questions considered to be important or more common concerning the past four weeks. Higher scores correspond to situations of greater overload and stress. Therefore, most caregivers reported an impact of the disease on the dimensions related to financial burden, effectiveness and control mechanism, family support and satisfaction with the role and with the relative, as can be seen in Chart 3 .

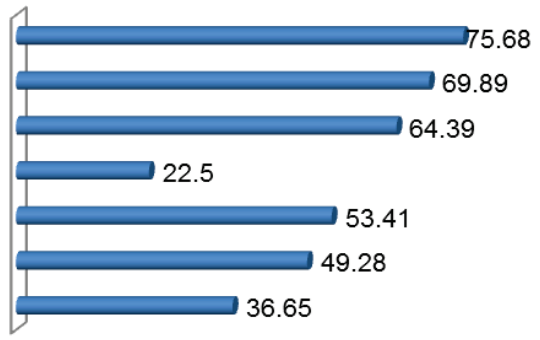

Figure 3. Assessment of the physical, emotional and social impact of the role of informal caregiver (QASCI).

When we analyzed the impact of each dimension on the caregivers, we noted that $50.1 \%$ of the caregivers had never or rarely been emotionally overloaded, whereas $86.4 \%$ of them had never or rarely felt reactions to demands. On the other hand, half of the sample mentioned that sometimes they had difficulties in the effectiveness and control mechanism. In relation to the caregiver, $36.4 \%$ of the participants mentioned that the stroke had never or rarely impacted their personal life. In relation to the financial burden, $45.4 \%$ of the caregivers mentioned experiencing it most of the times or always. Most caregivers mentioned that they experienced difficulties in family support most of the times or alwavs (68.2\%), as well as in the level of 
satisfaction with the role and with the relative (72.8\%). Given the fact that the person with aphasia is unable to answer the WHOQOL, only $45 \%$ of the participants completed the questionnaire.

The research results show that, on average, stroke patients have a set of limitations regarding their personal performance skills, since the most affected aspects of their health status were the physical dimension (49.0\%) and QoL in general (52.0\%). In a more intermediate context, we underline the psychological dimension (62.83\%) and, with better results, the dimensions related to social relationships and environment (63.67\%).

In relation to the caregiver, in the first moment, we observed a set of limitations related to the personal performance skills, since the most affected aspects of the health status were the physical dimension (54.67\%) and QoL in general (60.82\%). In a more intermediate position, we found the dimension related to the environment (62.93\%) and, with better levels of QoL, the psychological (65.95\%) and social relationships (69.07\%) dimensions.
We found differences between the QoL of stroke patients and the QoL of caregivers in the first moment. However, we noticed that, because caregivers have, on average, a better QoL in all dimensions, except for the environment, the difference was only statistically significant in the physical dimension $(p=0.04)$ at a level of significance of $5 \%$. At the 2-month follow-up, only eight people answered the questionnaire, i.e. $14.5 \%$ of the sample, which is a small percentage to draw any conclusions. We continued to identify a set of limitations related to the personal performance skills, such as the physical dimension (46.88\%) and QoL in general (48.44\%). We found the highest scores in the social relationships (59.38\%) and environment (55.86\%) dimensions, with the psychological dimension (46.88\%) being in an intermediate position. If we compare the data obtained in the first moment with those obtained in the second moment, we see that the QoL of stroke patients deteriorated in all dimensions, as can be seen in Figure 4.

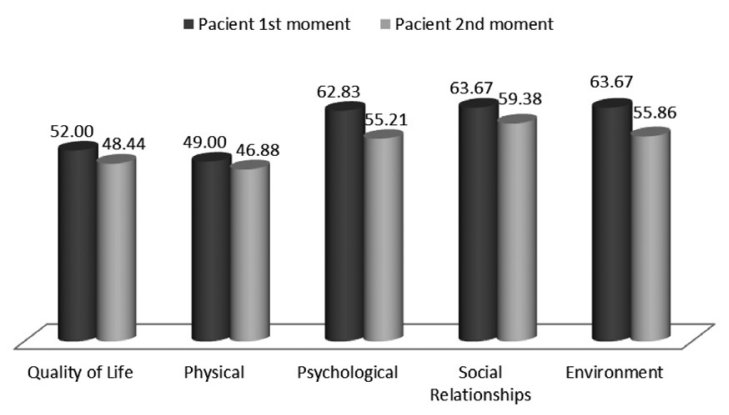

Figure 4. Dimensions of the patient's quality of life in the first and second moments.

In relation to the care provider, we also found that, in all dimensions, except for the physical dimension, two months after the stroke, the QoL had decreased as can be seen in Figure 5.

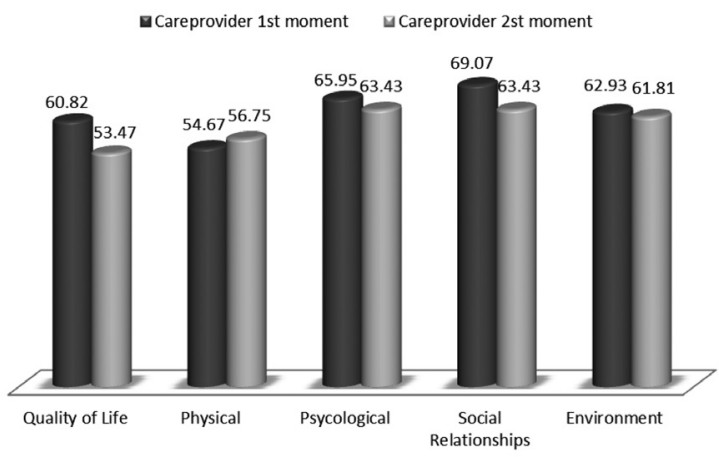

Figure 5. Dimensions of the caregiver's quality of life in the first and second moments 
In relation to the influence of gender in the perception of QoL of stroke patients, women scored higher in all dimensions, except for the psychological and environment dimensions. Female caregivers had a higher QoL than male caregivers in all dimensions.

\section{Discussion}

Out of the 55 stroke patients, $69.1 \%$ were male, a result that is in line with the literature review performed. According to Phipps, the incidence of stroke is higher in males (cited in Marques, 2012). Cerveira (2011), Pinto (2011) and Marques (2012) also corroborate these results with percentages of $52.6 \%, 52 \%$ and $60 \%$, respectively.

In relation to age, this ranged between 44 and 92 years, with $58.2 \%$ of the sample aged 70 years or more. The data confirm the predominance of stroke in older adults. In a study conducted by Cerveira (2011), the mean age was 73 years. Pinto (2011) also concluded that the mean age of the studied population was 73.7 years.

In this study, $68.55 \%$ of the stroke patients were married, which is consistent with most of the studies consulted. In the study conducted by Cerveira (2011) and in the study by Pinto (2011), 57\% and 48\%, respectively, of the stroke patients were married. Marques (2012) also concluded that $61 \%$ of the study participants were married.

We found that a large percentage of patients has a low level of education. Several studies mention that low education leads to low socio-economic income, less concern with risk factors for health and, consequently, lower disease prevention. Cerveira (2011) and Pinto (2011) corroborate this statement, being that, in both studies, most patients attended only the first cycle of basic education or less.

In relation to the type of stroke, $76.4 \%$ of the patients were diagnosed with ischemic strokes and $23.6 \%$ with hemorrhagic strokes, which is in line with the values usually found.

We had some limitations in this study, namely the limited number of participants at the 2-month follow-up after the stroke (only 14.5\%). It seemed to us that only a few caregivers wanted the stroke patient to return home after discharge. On the other hand, there are also clinical recommendations for forwarding patients to the National Integrated Long-Term Care
Network. We also faced many difficulties in collecting data at the 2-month follow-up after discharge.

However, at the reassessment two months after discharge, we found that the dimensions related to the physical performance and the QoL in general had the worst scores among caregivers, reflecting the impact of the stroke on the caregivers and confirming that the disease and the disability affect both physical performance and QoL. The social relationships and the psychological dimension were less affected, although the scores were not very high.

We conclude that there were differences in the QoL of patients and caregivers in the second moment of assessment, and that the caregivers had better levels of QoL than the stroke patients, although the difference was not statistically significant $(p>0.05)$.

\section{Conclusion}

This research focused on patients diagnosed with ischemic or hemorrhagic stroke who were moderately or highly dependent, and were hospitalized in the Stroke Unit of the Baixo Vouga Hospital Center, and respective caregivers.

This study aimed to determine the QoL of patients and caregivers. We found that almost all variables influence QoL.

In view of the results obtained, we concluded that a large percentage of stroke patients are forwarded to Integrated Long-Term Care Units. Many care providers revealed that they have no conditions to care for their relative at home, either due to their daily demands, such as their profession, or due to financial reasons. In other cases, patients have no family members close to take care of them or live alone because their children have emigrated, their spouses have died or they have no children.

Most caregivers feel the impact of their relative's disease and report facing great difficulties, with a greater overburden due to lack of professional support, problems related to the patient and inadequate family support.

This study allowed identifying the QoL of stroke patients hospitalized in the Stroke Unit of the Baixo Vouga Hospital Center and respective caregivers, as well as the association between QoL and sociodemographic and health variables. Therefore, it gave us an opportunity to think of a set of 
recommendations that can lead to a better perception of QoL in both the patients and the caregivers.

Since the QoL of patients and caregivers is affected after a stroke in which the patient has some degree of dependence, it seems to us that our role as health professionals is determinant to help caregivers and patients deal with this new reality, namely through educational interventions.

We believe that a better collaboration between all the means and resources of the National Health System (primary health care, hospitals, integrated long-term care network) could benefit patients and caregivers. We often asked ourselves throughout this study if it would be better for patients and caregivers to have patients returning home after hospital admission and health professionals going to their homes and helping them adapt to a new reality. This would clearly involve a change in the current paradigm of the National Health System.

We believe that further studies in this area should include the patients' aphasia as an exclusion criterion of participation in the study.

We believe that this study is relevant from a theoretical perspective as it contributes to the promotion of scientific knowledge. We recommend that further studies be conducted in this area.

\section{References}

Alves S., Rodrigues, R., Fernandes, S., Vieira, H., \& Fragoeiro, I. (2012). Avaliação da depressão pós AVC em pacientes com afasia. Revista Sinapse, 12(1), 239-240.

Batista, M. V. (2012). Generalidades sobre AVC no adulto jovem. Revista Sinapse, 12(1), 206.
Brito, L. (2002). A saúde mental dos prestadores de cuidados a familiares idosos. Coimbra: Quarteto Editora ISBN:9789728717193

Campos, M. O., \& Neto, J. F. (2008). Qualidade de vida: Um instrumento para promoção de saúde. Revista Baiana de Saúde Pública, 32(2), 232-240.

Cerveira, J. A., (2011). Independência funcional nos pacientes com AVC: Determinantes sociodemográficas e clínicas (Dissertação de mestrado). Retrieved from http:/hdl.handle. net/10400.19/1616

Instituto Nacional de Estatística. (2010). Anuário Estatístico 2010. Retrieved from https://www.ine.pt/xportal/ xmain?xpgid $=$ ine_main\&xpid $=I N E \& x l a n g=p t$

Leal, C. (2008). Reavaliar o conceito de qualidade de vida (Dissertação de mestrado). Universidade dos Açores, Ponta Delgada, Portugal.

Marques, F. M. (2012). Independência funcional do paciente pós AVC (Dissertação de mestrado). Retrieved from http://hdl. handle.net/10400.19/1619

Martins, T., Ribeiro, J. L., \& Garret, C. (2003). Estudo de Validação do Questionário de Avaliação da Sobrecarga para Cuidadores Informais. Psicologia Saúde E Doenças 4 (1), 131-148.

Ordem dos Enfermeiros, Conselho de Enfermagem. (2009). Rede Nacional de Cuidados Continuados Integrados: Referencial do enfermeiro. Retrieved from http://www. ordemenfermeiros.pt/documentosoficiais/Documents/ RNCCI\%20-\%20v.FINAL\%20Referencial\%20do\%20 Enfermeiro\%20-\%20Abril\%202009.pdf

Pinto, E. M. (2011). Independência funcional e regresso ao domicílio: Variável chave para a enfermagem de reabilitação (Dissertação de mestrado). Retrieved from http:/hdl.handle.net/10400.19/1617

World Health Organization. (1997). Countries - Portugal Retrieved from http://www.who.int/countries/prt/en/ 
